\title{
Desalinated and blended water in Saudi Arabia: human exposure and risk analysis from disinfection byproducts
}

\author{
Imran Rahman Chowdhury ${ }^{1}$, and Shakhawat Chowdhury ${ }^{2 *}$ \\ ${ }^{1}$ King Fahd University of Petroleum and Minerals, Dhahran, Dhahran 31261, Saudi Arabia \\ ${ }^{2}$ King Fahd University of Petroleum and Minerals, Dhahran, Dhahran 31261, Saudi Arabia
}

\begin{abstract}
Saudi Arabia produces the largest amount of desalinated water as a single country. The desalinated water is typically blended with treated groundwater, $\mathrm{pH}$ adjusted and chlorinated prior to supply to the communities. The desalinated seawater and/or blended water contains various types of disinfection byproducts (DBPs), some of which may induce cancer risks to human through lifetime exposure. In this study, occurrences of trihalomethanes (THMs) in desalinated and blended water in Saudi Arabia were investigated and their exposure and risks were predicted. The chronic daily intakes of $\mathrm{CHCl}_{3}, \mathrm{BDCM}, \mathrm{DBCM}$ and $\mathrm{CHBr}_{3}$ were estimated to be $8.38 \times 10^{-5}, 7.57 \times 10^{-5}, 2.54 \times 10^{-5}$ and $4.32 \times 10^{-4} \mathrm{mg} / \mathrm{kg}$-day respectively. The overall cancer risk was $1.78 \times 10^{-5}$ with the range of $7.40 \times 10^{-7}-9.26 \times 10^{-}$ 5 and the average hazard index was $3.49 \times 10^{-2}$ with the range of $1.20 \times 10^{-3}-$ $2.34 \times 10^{-1}$. The loss of disability adjusted life years (DALY) were estimated to be 25.1 per year and the average cancer risk had $8.48 \times 10^{-7}$ DALY per person per year. The financial burden was estimated to be US $\$ 2.72$ million with the range of US\$2.52-2.91 million. The findings may assist in better understanding and reducing cancer risks from DBPs in desalinated and blended water.
\end{abstract}

\section{Introduction}

Desalination of seawater has been in practice for satisfying domestic water demands in many countries in the Middle East, the Mediterranean Basin, as well as in Australia and USA. In the Arabian Gulf, total production of desalinated water was reported to be approximately 11 million $\mathrm{m}^{3}$ /day while Saudi Arabia produced approximately 4.5 million $\mathrm{m}^{3} /$ day $[1,2]$, which has made Saudi Arabia as the largest producer of desalinated water as a single country [1,2]. For desalination, two main processes: thermal (MSF: multi-stage flash; MED: multi effect distillation); and membrane (RO: reverse osmosis) are in practice, and the dominant process is MSF, due mainly to low energy cost in this region. In addition, large-scale plants with advanced technologies are being established in these countries indicating the increase in desalinated water supplies in future.

Corresponding author: schowdhury@kfupm.edu.sa 
The desalination plants receive feed water mainly from the open seawater intakes while some plants receive feed water via different intakes and coastal locations. The pretreatment is performed using continuous or intermittent chlorination with initial doses of $0.5-2.0 \mathrm{mg} / \mathrm{L}$ to achieve the target residuals of $0.25-0.5 \mathrm{mg} / \mathrm{L}$. Free chlorine is also applied in different stages of desalination process as well as in final disinfection. Consequently, different types of disinfection byproducts (DBPs) are formed in the desalinated seawater, which can pose public health risks. The average concentration of bromide in seawater from the Arabian Gulf was reported to be $64,000 \mu \mathrm{g} / \mathrm{L}$ [3]. Past studies have reported that seawater could contain bromide and iodide in the ranges of $50,000-80,000 \mu \mathrm{g} / \mathrm{L}$ and $21-60 \mu \mathrm{g} / \mathrm{L}$ respectively [35], which can increase the formation of brominated and iodinated DBPs. The brominated and iodinated DBPs are much more cytotoxic and genotoxic than the chlorinated DBPs [6].

In the past, many studies have focused on human exposure and risk from DBPs in freshwater sourced drinking water. Despite the public health relevance, not much is known about the DBPs in desalinated and blended water, their exposure and risk. In Saudi Arabia, desalinated water supplies more than $60 \%$ ( $\sim 1620$ million $\mathrm{m}^{3} /$ year) of domestic water demand [2], which is likely to be increased in future. The desalinated water is blended with the treated brackish groundwater, $\mathrm{pH}$ adjusted and chlorinated prior to supplying to the consumers. The blended water stays in the regional pipelines, storage tanks, blending stations and WDS for several days. In addition, maximum daily temperature during summer often exceeds $40^{\circ} \mathrm{C}$, which can increase the reaction rates by several folds. The water has the environments and constituents conducive to increased formation of DBPs, in particular, the brominated and iodinated DBPs [7]. There is a need to understand DBPs concentrations in desalinated and blended water, and the consequent exposure and risk. In this study, formation and distribution of THMs in desalinated and blended water from different desalination plants in Saudi Arabia were investigated. Exposure to THMs were estimated through ingestion, inhalation and dermal absorption pathways. Cancer and non-cancer risks were predicted which were used to predict the societal burden in terms of disability adjusted life year (DALY) applying the concept of YLL (years of life lost due to premature mortality) and YLD (years of life lost due to disability).

\section{Methodology}

\subsection{Data Collection}

Occurrences of THMs (chloroform: $\mathrm{CHCl}_{3}$; bromodichloromethane: BDCM; dibromochloromethane: $\mathrm{DBCM}$; and bromoform: $\mathrm{CHBr}_{3}$ ) and water quality parameters were investigated in desalinated seawater and blended water (mixture of desalinated seawater and treated groundwater in the ratio of 40-60\%) in the WDS in Al-Khobar and Dhahran, Saudi Arabia for a period of one year (Feb, 2014 - Jan 2015). The samples were collected on biweekly basis and analyzed in duplicates following the standard methods $[8,9]$.

\subsection{Exposure and Risk Assessment}

Exposure to THMs occurs through multiple pathways, including ingestion of drinking water, and inhalation and dermal contact during showering, bathing, house cleaning and swimming [10]. To incorporate uncertainty, 5000 random data are generated for each parameter following the statistical distributions. Exposure to THMs through ingestion is predicted using the THMs in cold water. THMs exposure through inhalation pathway is predicted using THMs in the shower air, which is estimated using the partition coefficients and mass-balance equations. In assessing dermal exposure during showering, showering events are divided into 
the unsteady and steady states and exposure. Moreover, to incorporate the higher level of exposure during early life adjustment factor was used (i.e. adjustment factor of 10 fold and 3 fold for the age group $<2$ years and $2-16$ years, respectively; no adjustment factor for the age group $>16$ years) [11]. Further details are summarized below.

\subsubsection{Ingestion pathway}

The chronic daily intakes (CDI) of THMs through ingestion of drinking water is computed following USEPA [7, 12-14] as:

$$
C D I_{\text {ing }}=\frac{C_{w} \times E F \times I R \times E D \times C F}{B W \times A T}
$$

Where, $\mathrm{CDI}_{\text {ing }}=\mathrm{CDI}$ via ingestion ( $\mathrm{mg} / \mathrm{kg}$-day); $\mathrm{C}_{\mathrm{w}}=$ THMs concentrations in drinking water $(\mu \mathrm{g} / \mathrm{L}) ; \mathrm{EF}=$ frequency of exposure (days/year); IR = rate of drinking water ingestion (L/day); $\mathrm{ED}=$ duration of exposure (year); $\mathrm{BW}=$ weight of the body $(\mathrm{kg}) ; \mathrm{AT}=$ averaging time (days); and $\mathrm{CF}=0.001$ (conversion factor of mass from $\mu \mathrm{g}$ to $\mathrm{mg}$ ).

\subsubsection{Inhalation pathway}

The CDI of THMs through inhalation pathway is predicted following USEPA [7, 12-14] as:

$$
C D I_{\text {inh }}=\frac{E_{r} \times C_{a} \times t \times R \times F \times E F \times E D \times C F}{B W \times A T}
$$

Where, $\mathrm{CDI}_{\text {inh }}=\mathrm{CDI}$ via inhalation (mg/kg-day); $\mathrm{E}_{\mathrm{r}}=\mathrm{THMs}$ absorption rate in respiratory system; $\mathrm{t}=$ shower duration $(\mathrm{min} / \mathrm{shower}) ; \mathrm{R}=$ breathing rate $\left(\mathrm{m}^{3} / \mathrm{min}\right) ; \mathrm{F}=$ shower frequency (shower/day); $\mathrm{CF}=0.001$ (conversion factor of mass from $\mu \mathrm{g}$ to $\mathrm{mg}$ ); and $\mathrm{C}_{\mathrm{a}}=$ concentrations of THM in shower air $\left(\mu \mathrm{g} / \mathrm{m}^{3}\right) . \mathrm{C}_{\mathrm{a}}$ depends on various factors, including water flow rate of shower, shower stall volume, THMs in cold water, mass transfer rate, shower duration and exchange rate of shower air. $\mathrm{C}_{\mathrm{a}}$ is be modeled following Chowdhury (2013) [7].

\subsubsection{Dermal contact pathway}

THMs can be absorbed through human skin during showering. Human skin is a complex organ, which acts as a barrier to chemical intrusion through dermal pathway. Depending on shower duration, dermal exposure often needs unsteady and steady state exposure assessments while unsteady state exposure can be different from the steady state assessments [7]. However, diffusion of chemicals before reaching steady state can be significantly different from the steady state values [15]. To achieve steady state between the chemicals in water attached to the skin surface (i.e. upper layer of stratum corneum) and lower layer of stratum corneum, there is a need of lag time, which was reported to be in the range of 9.8 391.2 minutes for different DBPs [7]. The lag time prior to achieving steady state condition, diffusion through skin, octanol-air partition coefficient, CDI during unsteady and steady states are estimated following past studies [7, 16]. Upon estimation of CDI through the unsteady and steady states of exposure, the total CDI through dermal route is calculated as:

$$
C D I_{\text {derm }}=C D I_{\text {derm-ust }}+C D I_{\text {derm-ss }}
$$


Where, $\mathrm{CDI}_{\text {derm-ust }}=\mathrm{CDI}$ of THMs during unsteady-state period $\left(\mathrm{mg} / \mathrm{kg}\right.$-day); $\mathrm{CDI}_{\text {derm-ss }}$ $=\mathrm{CDI}$ of THMs through dermal route $\left(\mathrm{mg} / \mathrm{kg}\right.$-day) during steady-state condition; $\mathrm{CDI}_{\text {derm-ss }}$ $=$ total CDI through dermal route. Upon estimation of route specific CDI, lifetime cancer and non-cancer risks can be estimated as:

$$
\begin{gathered}
C R=\sum_{i=1}^{m} \sum_{j=1}^{n} C D I_{i j} \times S F_{i j} \\
H I=\sum_{i=1}^{m} \frac{C D I_{i}}{R_{f} D}
\end{gathered}
$$

Where, $\mathrm{i}=1,2,3 \ldots \mathrm{m}$ represent different THMs (i.e. $\mathrm{CHCl}_{3}, \mathrm{BDCM}, \mathrm{DBCM}$ and $\mathrm{CHBr}_{3}$ ); $\mathrm{j}=1,2,3 \ldots \mathrm{n}$ representing different routes of exposure (i.e. ingestion, inhalation and dermal contact $) ; \mathrm{CR}=$ cancer risk; $\mathrm{SF}=$ slope factor $\left([\mathrm{mg} / \mathrm{kg} / \text { day }]^{-1}\right)$ for specific route; $\mathrm{R}_{\mathrm{f}} \mathrm{D}=$ reference dose $\left(\mathrm{mg} / \mathrm{kg} /\right.$ day). The oral SF for BDCM, DBCM and $\mathrm{CHBr}_{3}$ are $0.062,0.084$ and 0.0079 per $\mathrm{mg} / \mathrm{kg}$-day respectively [17], while for the other routes, SF data are not available. In this study, oral SF from USEPA were used to estimate human health risk. The $\mathrm{R}_{\mathrm{f}} \mathrm{D}$ for $\mathrm{CHCl}_{3}, \mathrm{BDCM}, \mathrm{DBCM}$ and $\mathrm{CHBr}_{3}$ are $0.01,0.02,0.02$ and $0.02 \mathrm{mg} / \mathrm{kg}$-day respectively [17].

\subsubsection{DALY analysis}

The disability adjusted life year (DALY) estimates the number of years lost due to premature death and disability because of a disease or injury [18]. To asses DALY, three possible scenarios are considered: (i) a proportion of affected people will die from cancer; (ii) a proportion will be cured from cancer; and (iii) rest of them will live with cancer sequelaes. The healthy years of life lost in a group of populations is calculated following Soerjomataram et al. (2012) [19] as:

$$
D A L Y=Y L L+Y L D
$$

Where, DALY = total disability adjusted years of life lost; YLL = total years of life lost due to premature death from cancer; YLD = total years of life lost due to disability. YLL is calculated by multiplying the number of death with the years of life expected to live at the time of death. YLD is calculated by multiplying the incidence rate with the disable years caused by the disease and severity of the disease (e.g., disability weight). YLL and YLD were estimated following Pan et al., (2014) [20] as:

$$
\begin{gathered}
Y L D=\sum_{x} n_{x} P_{x}\left(1-S_{x}\right)\left(e_{x}-T_{D}\right) \\
Y L D=\sum_{x} n_{x} P_{x}\left[\left(1-S_{x}\right) D W_{y} L_{y}+S_{x}\left\{D W_{y} L_{y}+P_{s e q} D W_{s e q}\left(e_{x}-T_{D}\right)\right\}\right]
\end{gathered}
$$

Where, $\mathrm{n}_{\mathrm{x}}=$ number of population for each age group; $\mathrm{e}_{\mathrm{x}}=$ standard life expectancy, as reported in the Global Burden of Disease Studies (GBDS) [18]; $\mathrm{T}_{\mathrm{D}}=$ median time to die (e.g., 2.20 years for bladder cancer) [21]. DW = adjusted disability weight (range: 0.0 - 1.0) obtained from GBDS [18]; $\mathrm{L}=$ duration of disability, which is divided into three stages: time 
for diagnosis and treatment $\left(\mathrm{L}_{\mathrm{D}}\right)$ times for pre-terminal stage $\left(\mathrm{L}_{\mathrm{M}}\right)$ and times for terminal stage $\left(\mathrm{L}_{\mathrm{T}}\right)$. The average values of $\mathrm{L}_{\mathrm{D}}, \mathrm{L}_{\mathrm{M}}$ and $\mathrm{L}_{\mathrm{T}}$ were reported to be 4,3 and 1 months respectively [19]. $\mathrm{P}_{\mathrm{seq}}=$ proportion of the various sequelaes; $\mathrm{DW}_{\mathrm{seq}}=$ disability weight of various sequelaes; $\mathrm{T}_{\mathrm{c}}=$ median time to cure for cancer (average: 4 years for bladder cancer) [21]; $\mathrm{P}_{\mathrm{x}}=$ age-specific cancer risk; $\mathrm{S}_{\mathrm{x}}=$ survival rate. $\mathrm{P}_{\mathrm{x}}$ and $\mathrm{S}_{\mathrm{x}}$ were estimated following Pan et al., (2014) [20].

\section{Results and discussion}

\subsection{Data statistics}

Concentrations of THMs and water quality parameters for the desalinated and blended water are shown in Table 1. Concentrations of THMs in blended water were significantly higher than that in the desalinated water (Table 1).

Table 1. Summary of water quality parameters and THMs in desalinated and blended water.

\begin{tabular}{|l|l|l|l|l|}
\hline \multirow{2}{*}{ Parameter } & \multicolumn{2}{|c|}{ Desalinated water } & \multicolumn{2}{c|}{ Blended water } \\
\cline { 2 - 5 } & Average & Range & Average & Range \\
\hline DOC $(\mathrm{mg} / \mathrm{L})$ & $0.78(0.33)$ & $0.39-1.68$ & $1.98(0.41)$ & $1.27-3.14$ \\
\hline TC $(\mathrm{mg} / \mathrm{L})$ & $0.55(0.09)$ & $0.33-0.72$ & $1.1(0.23)$ & $0.69-1.54$ \\
\hline FRC $(\mathrm{mg} / \mathrm{L})$ & $0.44(0.16)$ & $0.24-0.72$ & $0.82(0.23)$ & $0.07-1.29$ \\
\hline Bromide $(\mathrm{mg} / \mathrm{L})$ & $0.28(0.13)$ & $0.10-0.64$ & $0.30(0.21)$ & $0.18-0.76$ \\
\hline Water temperature $\left({ }^{\circ} \mathrm{C}\right)$ & $26.3(5.8)$ & $20-39$ & $25.4(6.4)$ & $19-37$ \\
\hline pH & $6.9(0.49)$ & $6.6-7.7$ & $7.13(0.12)$ & $6.7-8.1$ \\
\hline Turbidity $(\mathrm{NTU})$ & $0.21(0.09)$ & $0.13-0.38$ & $0.33(0.15)$ & $0.14-0.46$ \\
\hline UV $254(/ \mathrm{cm})$ & $0.02(0.01)$ & $0.01-0.04$ & $0.04(0.01)$ & $0.02-0.058$ \\
\hline Conductivity $(\mu \mathrm{S} / \mathrm{cm})$ & $230.4(43.9)$ & $149-348.7$ & $415.3(72.4)$ & $266.4-552.5$ \\
\hline THMs $(\mu \mathrm{g} / \mathrm{L})$ & $10.08(2.1)$ & $0.1-33.6$ & $19.2(4.7)$ & $2.1-52.4$ \\
\hline
\end{tabular}

DOC: Dissolved organic matter; TC: total chlorine; FRC: Free residual chlorine; Values within brackets are standard deviations

Table 2. Concentration of THMs $(\mu \mathrm{g} / \mathrm{L})$ in desalinated and blended water in gulf countries.

\begin{tabular}{|c|c|c|c|c|c|}
\hline Country & THMs & Averag & Std. dev. & Min & Max \\
\hline \multirow{4}{*}{$\begin{array}{l}\text { Saudi } \\
\text { Arabia }\end{array}$} & $\mathrm{CHCl}_{3}$ & 0.71 & & 0 & 9.3 \\
\hline & BDCM & 0.86 & & 0 & 7.77 \\
\hline & DBCM & 1.46 & & 0 & 13.73 \\
\hline & $\mathrm{CHBr}_{3}$ & 15.74 & & 0 & 62.42 \\
\hline \multirow{4}{*}{ Qatar } & $\mathrm{CHCl}_{3}$ & 0.6 & & 0.01 & 4.96 \\
\hline & BDCM & 0.21 & & 0.01 & 2.66 \\
\hline & DBCM & 0.52 & & 0.01 & 2.74 \\
\hline & $\mathrm{CHBr}_{3}$ & 20.89 & 15.2 & 3.99 & 72.95 \\
\hline \multirow{4}{*}{ Kuwait } & $\mathrm{CHCl}_{3}$ & 0.81 & 1.13 & 0 & 5.87 \\
\hline & BDCM & 2.44 & 0.84 & 0.99 & 7.87 \\
\hline & DBCM & 6.63 & 2.11 & 2.74 & 13.73 \\
\hline & $\mathrm{CHBr}_{3}$ & 30.16 & 19.6 & 3.38 & 77.42 \\
\hline \multirow{4}{*}{ Bahrain } & $\mathrm{CHCl}_{3}$ & & & & \\
\hline & BDCM & 0.6 & 0.12 & & \\
\hline & DBCM & 0.64 & 0.05 & & \\
\hline & $\mathrm{CHBr}_{3}$ & 5.9 & 0.15 & & \\
\hline
\end{tabular}


In this study, average concentrations of THMs in the desalinated and blended water were 10.08 and $19.2 \mu \mathrm{g} / \mathrm{L}$ respectively with the ranges of $0.1-33.6$ and $2.1-52.4 \mu \mathrm{g} / \mathrm{L}$ respectively (Table 1). Concentrations of THMs in desalinated and blended water from few other plants in Saudi Arabia, and some Arabian Gulf countries are summarized in Table 2.

In the major cities of Saudi Arabia, THMs in desalinated water were in the range of 0.1 $-41.7 \mu \mathrm{g} / \mathrm{L}$ [22]. In blended water, THMs were in the ranges of $0.1-66.7 \mu \mathrm{g} / \mathrm{L}[5,23]$. THMs in the desalinated and blended water from Bahrain, Kuwait, Qatar and UAE were in the ranges of $0.27-6.4,7.11-104.89,4.02-83.31$ and $7.0-15.0 \mu \mathrm{g} / \mathrm{L}$ respectively (Table 2). Figure 1 shows the concentration variability of THMs in Saudi Arabia. On average, $\mathrm{CHCl}_{3}, \mathrm{BDCM}, \mathrm{DBCM}$ and $\mathrm{CHBr}_{3}$ were approximately 5.2, 6.2, 9.5 and $79.1 \%$ respectively.

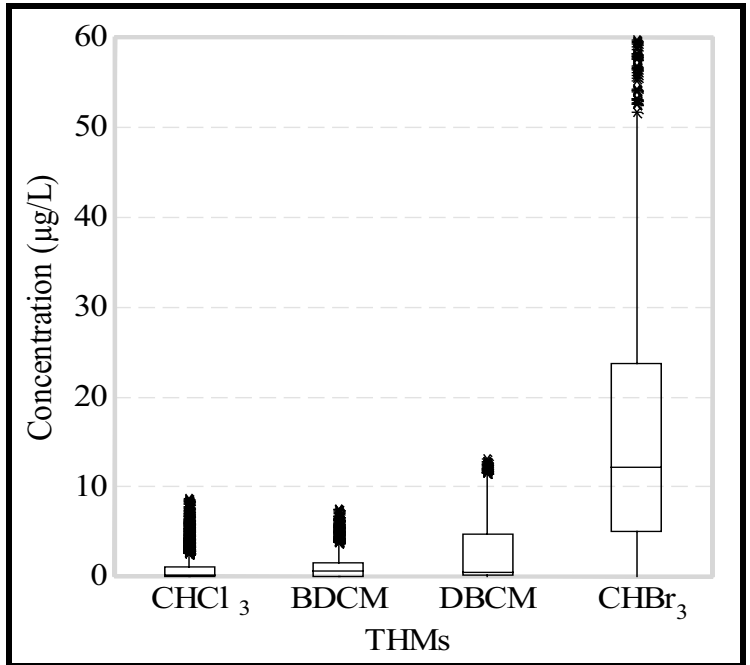

Fig. 1. Concentration of THMs in desalinated and blended water in Saudi Arabia. The bottom of the box and top of the box are the first quartile (Q1) - 25\% of the data values and the third quartile (Q3) $75 \%$ of the data values, respectively; the upper whisker and lower whisker extend to the highest data value within the upper limit: $\mathrm{Q} 3+1.5 *(\mathrm{Q} 3-\mathrm{Q} 1)$ and to the lowest value within the lower limit: $\mathrm{Q} 1-$ $1.5^{*}(\mathrm{Q} 3-\mathrm{Q} 1)$, respectively; Values beyond the whiskers are outliers; the horizontal bar in the middle of box is the median of the data values.

The THMs database obtained in this study was expanded using additional data from the desalinated and blended waters in different desalination plants and WDS in the major cities in Saudi Arabia [5, 7, 16, 22-25]. Using the combined data, the best-fit statistical distributions were developed for THMs. In this study, $\mathrm{CHCl}_{3}$ and $\mathrm{BDCM}$ followed triangular distribution while DBCM and $\mathrm{CHBr}_{3}$ followed the Gamma distribution (Table 3).

Table 3. THMs concentration $(\mu \mathrm{g} / \mathrm{L})$ in desalinated water in Saudi Arabia.

\begin{tabular}{|l|c|c|l|}
\hline THMs $_{1}$ & Average & Range & Distribution \\
\hline $\mathrm{CHCl}_{3}$ & 0.71 & $0.0-9.30$ & $\mathrm{~T}(0.0,0.76,9.3)$ \\
\hline $\mathrm{BDCM}$ & 0.86 & $0.0-7.87$ & $\mathrm{~T}(0.0,0.98,7.87)$ \\
\hline DBCM & 1.46 & $0.0-13.73$ & $\operatorname{Gamma}(0.4626,2.028,0.0111)$ \\
\hline $\mathrm{CHBr}_{3}$ & 15.74 & $0.0-62.42$ & $\operatorname{Gamma}(1.043,13.77)$ \\
\hline
\end{tabular}

Table 4. Proportion and disability weight (DW) for bladder cancer.

\begin{tabular}{|l|l|l|}
\hline Sequelae & Proportion (\%) & $\mathrm{DW}$ \\
\hline Incontinence & 5 & 0.157 \\
\hline Impotence & 10 & 0.195 \\
\hline Primary infertility & 16 & 0.18 \\
\hline
\end{tabular}


Secondary infertility $16 \quad 0.1$

The proportion of various sequelaes and disability weight of various sequelaes are shown in Table 4. The other relevant parameters for estimating exposure and risk assessment are obtained from previous studies [7, 13-17, 20, 26].

\subsection{Chronic daily intake of THMs}

The CDI for $\mathrm{CHCl}_{3}$, DBCM, BDCM and $\mathrm{CHBr}_{3}$ contributed 13.6, 12.3, 4.1 and $70.0 \%$ of total CDI respectively. On average, ingestion, inhalation and dermal routes contributed approximately $63.4,22.3$ and $14.3 \%$ of total CDI, respectively. The average $\mathrm{CDI}$ of $\mathrm{CHCl}_{3}$, $\mathrm{BDCM}, \mathrm{DBCM}$ and $\mathrm{CHBr}_{3}$ through all routes were $8.38 \times 10^{-5}, 7.57 \times 10^{-5}, 2.54 \times 10^{-5}$ and $4.32 \times 10^{-4} \mathrm{mg} / \mathrm{kg}$-day respectively while their ranges were $6.22 \times 10^{-7}-3.97 \times 10^{-4}, 1.14 \times 10^{-6}$ $-3.57 \times 10^{-4}, 1.20 \times 10^{-7}-5.33 \times 10^{-4}$ and $7.62 \times 10^{-8}-4.92 \times 10^{-3} \mathrm{mg} / \mathrm{kg}$-day respectively. The frequency distribution of CDI through all routes are shown in Figure 2. The CDI of $\mathrm{CHCl}_{3}$ and BDCM followed lognormal distribution whereas, the CDI of BDCM and $\mathrm{CHBr}_{3}$ followed Gamma distribution (Figure 2). The frequency distributions for $\mathrm{CHCl}_{3}, \mathrm{BDCM}$, $\mathrm{DBCM}$ and $\mathrm{CHBr}_{3}$ showed skewed distributions with right sided long tail, indicating that these fractions of data might pose elevated risk to human.

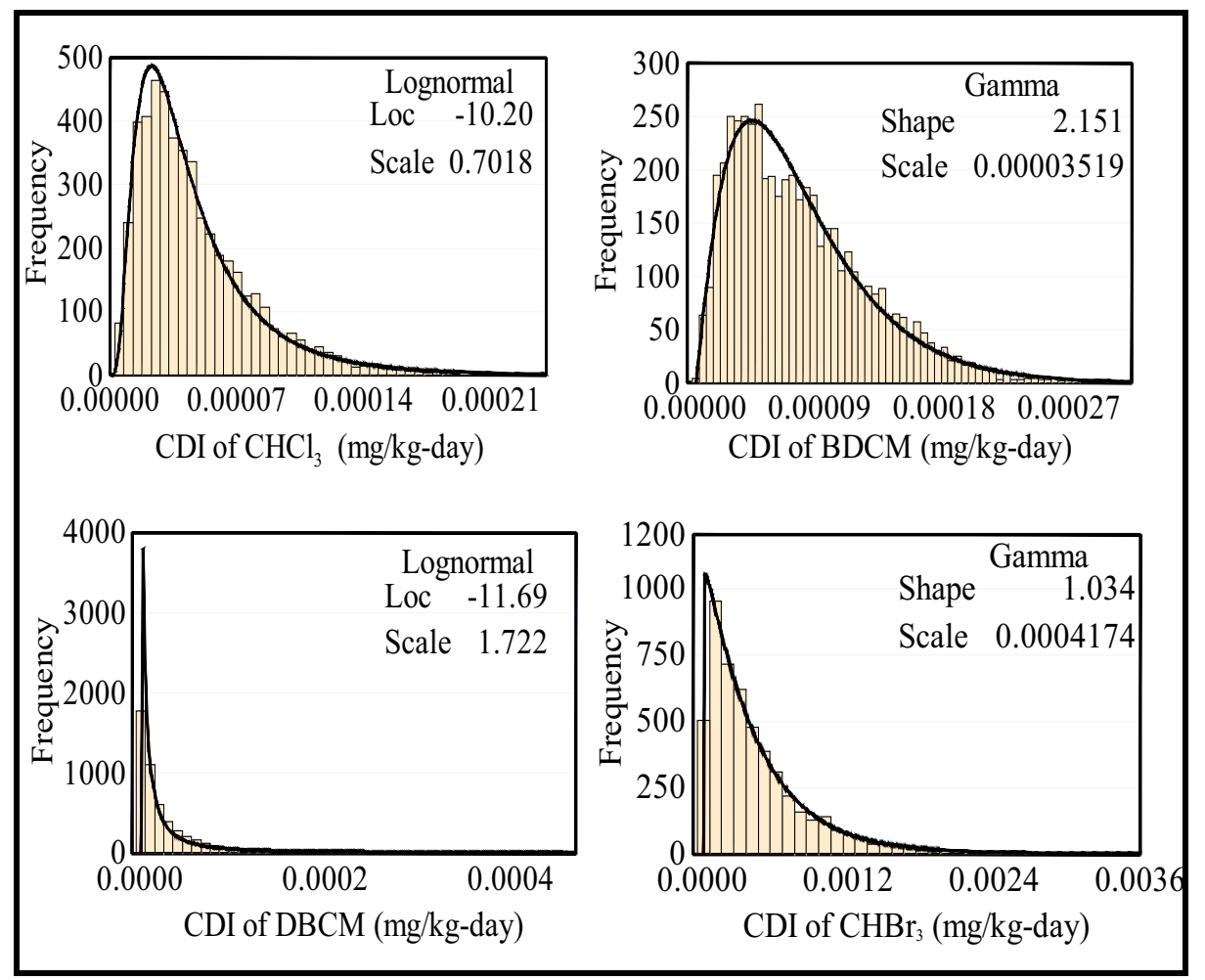

Fig. 2. Frequency distribution and fits of CDI of THMs.

\subsection{Risks of THMs}

The lifetime excess cancer risks and hazard indices are shown in Table 5. The average cancer risk considering all age groups was predicted to be $1.78 \times 10^{-5}$ with range of $7.40 \times 10^{-7}-$ $9.26 \times 10^{-5}$. The ingestion, inhalation and dermal routes contributed approximately $65.4,23.5$ 
and $11.1 \%$ of overall cancer risks. With respect to age groups, average cancer risks during $<2$ years, $2-16$ years and $>16$ years were $4.5 \times 10^{-6}, 5.2 \times 10^{-6}$ and $8.0 \times 10^{-6}$ respectively. These three age groups contributed approximately $25.4,29.3$ and $45.3 \%$ of total cancer risks respectively. In the early life, despite the exposure was only for 2 years, it contributed $25.4 \%$ of the overall risk, indicating that appropriate protection during this period (birth to $<2$ years) might reduce the overall risk significantly. The overall hazard index was estimated to be $3.49 \times 10^{-2}$ with the range of $1.20 \times 10^{-3}-2.34 \times 10^{-1}$. Hazard indices through ingestion, inhalation and dermal routes were estimated to be $2.23 \times 10^{-2}$ (range: $1.05 \times 10^{-3}-1.45 \times 10^{-1}$ ), $7.89 \times 10^{-3}$ (range: $1.21 \times 10^{-4}-8.18 \times 10^{-2}$ ) and $4.77 \times 10^{-3}$ (range: $3.84 \times 10^{-5}-4.53 \times 10^{-2}$ ) respectively (Table 5).

Table 5. Cancer risks and hazard indices for exposure to THMs.

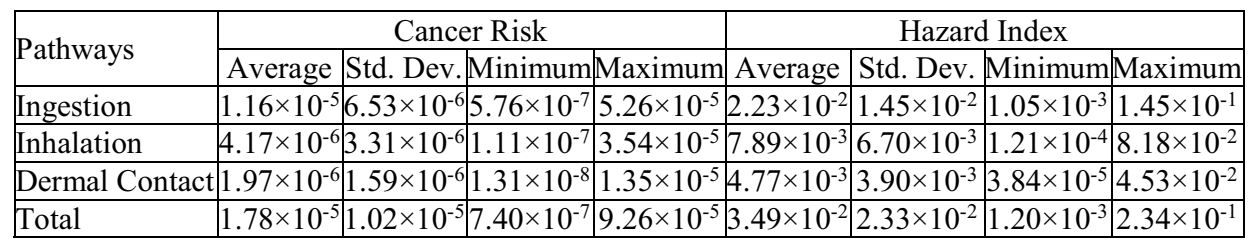

The overall DALY was estimated to be 25.1 with the range of $23.2-26.8$, meaning that on average 25.1 years are likely to be lost due to cancer risks from exposure to THMs. Among the DALY, the YLL and YLD were estimated to be $18.6(17.1-19.9)$ and $6.5(6.0-6.9)$ respectively. The YLL and YLD contributed approximately 74 and $26 \%$ of total DALY. DALY for different age groups are shown in Figure 3. The largest DALY (5.6) were estimated for 15-39 age group (Figure 3). The cancer risk in terms of DALY was obtained as $8.48 \times 10^{-7}$ per person per year (PPPY), which was lower than the USEPA guideline value of $1.0 \times 10^{-6}$ [27]. One DALY was associated with a loss of US\$ 108,600 [28], which means one year of healthy human life costs US\$ 108,600 , indicating that the total financial burden for Saudi Arabia was US\$2.72 million with the range of US\$2.52-2.91 million per year.

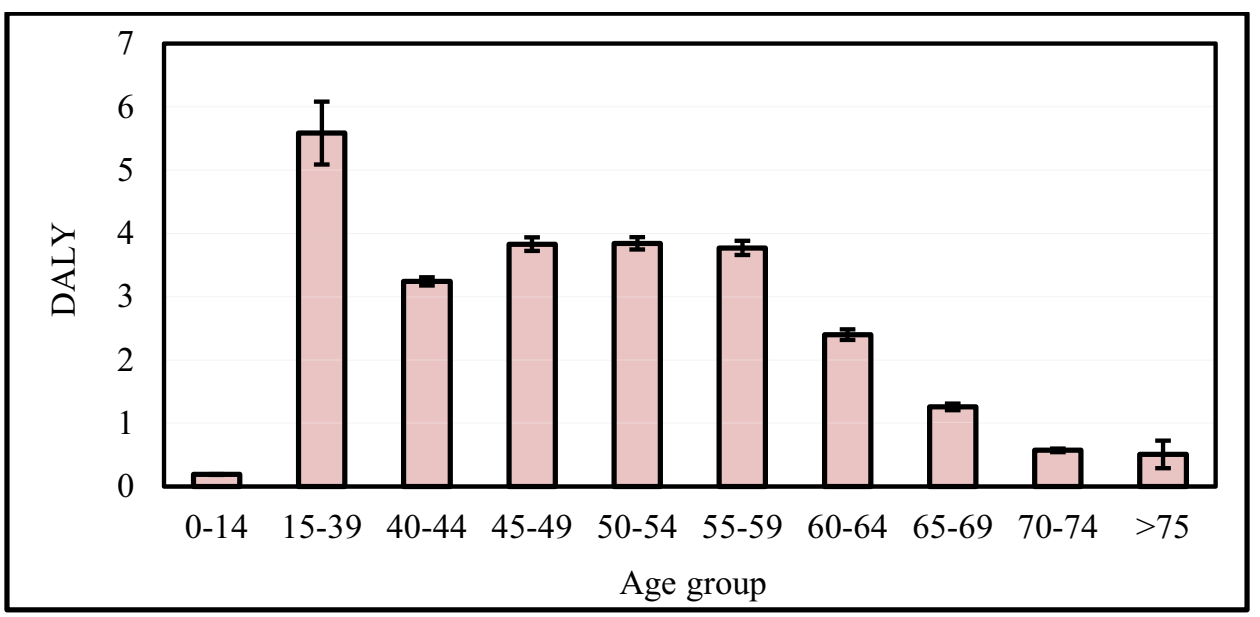

Fig. 3. DALYs for different age groups. Error bars represent standard deviation.

\section{Conclusion}

This study presented and applied the methodologies of estimating human health risk and DALY from exposure to DBPs in desalinated and blended water in Saudi Arabia. The cancer risks of DBPs in desalinated and blended water was predicted to be $1.78 \times 10^{-5}$, which was 
higher than the minimum risk recommended by the USEPA. Cancer risks through ingestion route was highest $(65.4 \%)$ followed by dermal $(23.5 \%)$ and inhalation $(11.1 \%)$ routes. With respect to age groups, the highest contributor group was $>16$ years $(45.3 \%)$, which had the largest lifespan (16+ to death). In contrast, the exposure during the early life (birth to $<2$ years) contributed approximately $25.4 \%$ of the overall risks. Control of early life exposure can reduce the risk significantly. The cancer risks in terms of DALY was estimated to be $8.48 \times 10^{-7}$ per person per year, which is below the reference risk level as recommended by the USEPA. The DALY can be used for analyzing financial burden from cancer risks. It can also be used for cost effectiveness analysis, which may help to improve quality of desalinated water and may help to prioritize the hazardous material present in desalinated water. In this study, THMs were used for analyses, which were a fraction of various DBPs present in desalinated water. Few other DBPs with possible cancer risks are HAAs, iodo-THMs, bromate, NDMA while sufficient information on these DBPs are not available to date to conduct risk analysis for desalinated and blended water. Future study may further look into these DBPs and their risks.

The authors would like to acknowledge the support of research group funding for the Water Research Group at the King Fahd University of Petroleum and Minerals (KFUPM), Dhahran 31261, Saudi Arabia.

\section{References}

1. M. Al-Zahrani, A. Musa, S. Chowdhury, S. Environ Dev Sustain, 18, 3, 777-798 (2016)

2. Ministry of Water and Electricity, The Ministry of Water and Electricity annual report, 2013, Saudi Arabia (2013)

3. A. Abdel-Wahab, A. Khodary, N. Bensalah, J. Environ. Prot., 1, 4, 456-465 (2010)

4. World Health Organization, Guidelines for drinking water quality (2010)

5. D. Kim, G. Amy, T. Karanfil, Water Res., 81, 343-355 (2015)

6. S.D. Richardson et al., Environ. Sci. Technol., 42, 22, 8330-8338 (2008)

7. S. Chowdhury, Sci Total Environ., 463-464, 922-930 (2013)

8. United States Environmental Protection Agency, Method 551.1 determination of chlorination disinfection byproducts, chlorinated solvents, and halogenated pesticides/herbicides in drinking water by liquid-liquid extraction and gas chromatography with electron-capture detection (1995)

9. American Public Health Association, Standard methods for the examination of water and wastewater (1998)

10. D.A. Savitz et al., Am J Epidemiol, 164, 11, 1043-1051 (2006)

11. United States Environmental Protection Agency, Supplemental guidance for assessing susceptibility from early-life exposure to carcinogens (2005a)

12. S. Chowdhury, P. Champagne, P.J. McLellan, Sci Total Environ., 407, 14, 4189-4206 (2009)

13. United States Environmental Protection Agency, Human health risk assessment protocol (1998)

14. United States Environmental Protection Agency, Human health risk assessment protocol for hazardous waste combustion facilities (2005b)

15. T.E. McKone, R.A. Howd, Risk Anal, 12, 4, 543-556 (1992)

16. S. Chowdhury, J Water Health, 14, 3, 489-503 (2016)

17. United States Environmental Protection Agency, Integrated risk information system: Online database, Available at: https://cfpub.epa.gov/ncea/iris2/atoz.cfm

18. C.J.L. Murray, A.D. Lopez, Harvard University Press, 1, 1-35 (1996)

19. I. Soerjomataram et al., BMC Medical Research Methodology, 12, 125 (2012) 
20. S. Pan et al., J. Hazard. Mater., 280, 288-294 (2014)

21. M. Smaastuen et al., Long-term cancer survival: patterns and trends in Norway 19652007, Cancer Registry of Norway (2008)

22. N.M. Fayad, J Am Water Works Assoc, 85, 1, 46-50 (1993)

23. J. Le Roux et al., Desalination, 359, 141-148 (2015)

24. M. Ahmad, A.S. Bajahlan, Environ Monit Assess, 159, 1-14 (2009)

25. P.C.M. Kutty, A.A. Nomani, T.S. Thankachan, Analyses of water samples from Jeddah seawater RO / MSF plants for organic pollutants, Issued as Technical Report No. SWCC (RDC)-14 (1991)

26. United States Environmental Protection Agency, Exposure factors handbook (2011)

27. United States Environmental Protection Agency, Risk Assessment Guidance for Superfund. Volume I: Human Health Evaluation Manual (Part A) (1989)

28. C.P. Lee, G.M. Chertow, S.A. Zenios, Value Health, 12, 1, 80-87 (2009) 